\title{
İletişim Çalışmalarında Medya Etnografisi Üzerine Bir Değerlendirme
}

\author{
A Review on Media Ethnography in Communication Studies
}

Ahmet Tarı TÜRKMENOĞLU*

\begin{abstract}
$\ddot{O} Z$
Günümüzde medyanın dünyanın her yanına hızlı bir şekilde yayılması ve insanların medyayı gündelik yaşamlarının bir parçası haline getirmesi toplumu anlama çabasında olan araştırmacıların medyaya yönelik ilgilerini arttırmıştır. Nitekim medya günümüz toplumlarının bu denli hayatına girmiş olmakla birçok açıdan toplumdaki değisşim ve dönüşümlerin katalizörü haline gelmiştir. Söz konusu bu değişim ve dönüşümleri medya özelinde ele alan araştırmalar tarihsel süreç içinde birçok yöntem kullanmıştır. Kullanılan bu yöntemlerin bazı eksikliklerinin olduğu yönündeki düşünceler medya çalışmalarında araştırmacıları yeni arayışlara yöneltmiştir. Bu arayışların bir sonucu olarak etnografi de medya çalışmalarında görece yeni kullanılmaya başlanan ve gittikçe hız kazanan bir yöntem olarak karşımıza çıkmaktadır. Bu çallş̧ma etnografik yöntemi medya özelinde tartışmaktadır. Bu anlamda medya çallşmalarında etnografik yöntemin kullanılmasının alana önemli bir katkı sağlayacağg, ancak etnografik yöntemin kriterlerine riayet edilmeden yürütülecek çalışmaların bu katkiyı engelleyebileceği gibi yöntemsel bir kargaşanın da ortaya çıkmasına neden olacă̆ değerlendirilmiştir.
\end{abstract}

\section{ANAHTAR KELIMELER}

Etnografi, Medya Etnografisi, Yöntem, Antropoloji

\begin{abstract}
At the present time, the rapid expansion of the media throughout the world and people's making it a part of their daily lives have increased the interest of the researchers who seek to understand the society in the media. As a matter of fact, with the media entering into the lives of contemporary societies on such a scale, it has become the catalyst on numerous counts for the changes and transformations in the society. Researches addressing these aforementioned changes and transformations in specific reference to the media have adopted multiple methods in the course of history. Considerations vis-à-vis these methods suffering from some shortcomings, however, led researchers to new quests in their media studies. As a consequence of the quests, inter alia, ethnography also presents itself as a relatively newly applied method in media studies, one that gains more and more momentum. This study discusses the ethnographic method in respect of the media. In this sense, it has been concluded that the application of the ethnographic method in media studies will make a significant contribution to the field, but studies to be conducted absent the fulfilment of the criteria thereof will nevertheless not only forestall this contribution but also engender a methodological confusion.
\end{abstract}

\section{KEYWORDS}

Ethnography, Media Ethnography, Method, Anthropology

\begin{tabular}{|c|c|c|}
\hline \multicolumn{2}{|c|}{ Makale Geliş Tarihi / Submission Date } & \multicolumn{1}{c|}{$\begin{array}{c}\text { Makale Kabul Tarihi / Date of Acceptance } \\
07.04 .2021\end{array}$} \\
\hline \multirow{4}{*}{ Atıf } & $\begin{array}{l}\text { Türkmenoğlu, A. T. (2021). İletişim Çalışmalarında Medya Etnografisi Üzerine Bir Değerlendirme. Selçuk } \\
\text { Üniversitesi Sosyal Bilimler Meslek Yüksekokulu Dergisi, 24 (1), 209-216. }\end{array}$ \\
\hline
\end{tabular}

\footnotetext{
* Dr. Öğr. Üyesi, Necmettin Erbakan Üniversitesi Sosyal ve Beşeri Bilimler Fakültesi, aturkmenoglu@erbakan.edu.tr, ORCID: 0000-0001-6791-4163
} 


\section{GİRIŞ}

Evreni ve burada cereyan eden olayları anlamak kadim bir tarihsel miras olarak yaşamaktadır. Anlama çabasının öznesi olarak konumlanan insan bunun için tarih boyunca çeşitli yol ve yöntemler geliştirmiştir. Gelinen noktada modern bilim bu anlama çabasının yürütüldüğü en belirgin saha olarak kendini var etmektedir. Modern bilim açısından doğa bilimleri olarak başlayan serüven insan ve toplum bilimlerine doğru genişlemiş, insanı ve toplumu anlama çabasına yönelik olarak çeşitli tartışmalar ortaya çıkmıştır. Genel hatlarıyla doğa bilimlerinin yönteminin sosyal bilimler için de geçerli olabileceği temel anlayışına sahip olan pozitivizm bu anlamda ilk bilimsel paradigma olarak doğmuş, pozitivizme karşı geliştirilen itirazlar neticesinde tartışmalar yorumsamacı yaklaşım, eleştirel yaklaşım ve çok daha yakın zamanların tartışması olarak postmodern ve feminist yaklaşımlar toplumu anlama çabasına yönelik ortaya çıkan bilimsel paradigmalar olarak kendisini göstermiştir (bkz. Neuman, 2020). Bilimsel çalışmalarda etnografik yöntem de bu anlama çabalarının bir parçası olarak ortaya çıkmıştır.

Medya ise modern dünyada insanı anlama çabaları içinde başat konular arasında yer almaktadır. Medyanın gücü ve bir kültür aracı olarak işlev görmesi, izleyicilere dünyayı görme ve yorumlama yolları sunması, (Spitulnik, 1993:293) toplumun sosyo-kültürel dönüşümünde önemli bir kaynak konumunda olmas1 (Postill, 2017:20) da medyanın etnografik bir araştırma sahası olarak belirmesini sağlamıştır. Medyanın toplum yaşamı üzerindeki bu tür etkileri göz önüne alındığında medyayla ilgili çözümlemelerin toplumsal yaşamın çözümlenmesi noktasında önemli veriler sağlayacağı söylenebilir. Nitekim medya ile yoğun bir şekilde dolayımlanan gündelik hayatın kendine özgü ritüelleri ve rutinleri olduğu düşünüldügünde, toplumsal yaşam içinde medya kültürlerini ve medya ritüellerini anlama açısından medya etnografisi yapmanın büyük önem taşıdığı görülmektedir (Çaylı Rahte, 2018:597).

Bu çalışma medyanın günümüzde toplumların değişim ve dönüşümlerini önemli ölçüde yönlendiren bir kaynak olduğu kabulüyle hareket ederek bu değişim ve dönüşümleri daha iyi anlama çabası olarak medya araştırmalarında son dönemlerde ağırlık kazanan bir araştırma yöntemi olan etnografiyi medya özelinde ele almaktadır. Çalışma medya etnografisi ya da medya antropolojisi olarak literatürde yer edinen bu alanla ilgili genel hatları ortaya koymayı amaçlamaktadır.

\section{ETNOGRAFİ: TANIM VE TARTIŞMALAR}

Kökenleri itibari ile 19. yüzyıl batı antropolojisine dayanan (Hammersley ve Atkinson, 2007: 2) toplumlara ve kültürlere yönelik sistematik bilgi üretme noktasında yaygın olarak kullanılan (Can, 2017:156), pozitivizmin kabullerine karşı olan yorumsamacı yaklaşım içinde gelişen ve bu anlamda Weberci geleneğe dayandırılabilecek etnografik yöntem insanın kendi kültürel varlığı içinde anlaşılabileceğini varsaymaktadır. Nitekim Geerzt (1973:5) Weber'e de atıfla kültürün insanın anlam dünyasını oluşturan bir ağ olduğunu ve bu anlam dünyasına atfetmiş olduğu önem dolayısıyla da bilimsel araştırmanın ampirik değil yorumlayıcı olması gerektiğini ileri sürmektedir. Bu anlamda etnografik araştırmanın mantı̆̆ ampirik araştırmaların temel yöntemine karşı geliştirdiği itiraza dayanmaktadır (Hammersly, 2006: 11)

İnsanların davranışlarını tam olarak hangi ölçüde ifade ettikleri "sormanın sınırları" ve " insanların her zaman söylediklerini yapmamaları" insan davranışı araştırmalarında problem teşkil eden iki önemli soruna işaret etmektedir (aktaran; Özbölük ve Dursun, 2015: 231). Bu noktada ampirik ya da nicel araştırmaların veri toplama sürecindeki yapılandırılmış karakterinin araştırmacının sosyal dünya hakkındaki varsayımlarının dayatılmasını içermesi ve sonuç olarak bu varsayımların dışında bir kanıtın bulunma şansını azaltması, araştırmacı tarafından özel olarak tasarlanmış ortamlarda üretilen verilere dayanarak 'doğal' ortamlarda neler olduğuna dair iddialarda bulunması, insanların inandıkları ve yaptıkları hakkında söylediklerine güvenmesi sonucu gözlemi ihmal etmesi, bundan dolayı da tutum ve davranış arasındaki karmaşık ilişkiyi açıklayamaması gibi bir takım eksiklikler etnografinin temel itiraz noktalarıdır (Hammersly, 2006: 11-12)

$\mathrm{Bu}$ doğrultuda etnografik araştırma insanların ne söylediğine değil ne yaptığına odaklanarak onların alışılagelmiş ve kültürel karmaşık davranışları hakkında konuşma ve bunlara bir açıklama getirmedeki yetersizliklerine cevap vermeyi (aktaran; Özbölük ve Dursun, 2015: 231) vaad eder. Bunu yaparken etnografik araştırma grup ya da kültürün bütününü, bileşenlerini, onların arasındaki ilişkileri o kültürün mensuplarının kendi gözünden görüp onların sahip olduğu kültür kodlarıyla anlamaya çalışır (Kartarı, 2017:217). Diğer bir ifade ile bu yöntem insanların doğa, kültür, nesneler, hayal gücü ve pratikle yani yaşamın tüm alanlarıyla ilişkilerini onların kendi terimleriyle anlamaya çalışır (Can, 2017: 156). Bu anlamda etnografik alan araştırması, insan topluluklarını gündelik yaşamları içerisinde ele alarak inceleyen bir yöntemdir (Emerson, Fretz ve Shaw, 2015: 1). Bir başka deyişle etnografik araştırma insan davranışını deneysel tasarımlarda veya yüksek düzeyde yapılandırılmış görüşme durumlarında olduğu gibi araştırmacı tarafından oluşturulan koşullar yerine günlük bağlamlarda ele alır (Hammersly ve Atkinson, 2007:3). 
Etnografik araştırma sürecinde başlıca iki faaliyet alanı söz konusudur. İlk olarak etnograf genellikle daha önceden birebir bilgi sahibi olmadığı belirli bir sosyal düzen içerisine girerek bu düzen içinde yaşayan insanları tanımaya çalışır. Bu aşamada etnograf, düzeni oluşturan gündelik rutine dahil olarak burada diğer insanlarla sürekli bir ilişki geliştirir ve bu sayede olan biten her şeyi bu katılım esnasında gözlemler. Sık sık ifade edilen "katılımc1-gözlem" terimi de araştırmanın bu temel yaklaşımını vurgulamak için kullanılır. Etnografin araştırma sürecinde ikinci olarak yaptığı şey ise katılım sağladığ düzen içinde insanların gündelik olarak yapıp ettiklerine ilişkin gözlemlerini ve öğrendiklerini düzenli ve sistemli bir şekilde kaydetmektir. Böylelikle araştırmacının elinde incelediği insan gruplarına dair gözlemlerinin ve tecrübelerinin yazılı kayıtlarını içeren bir birikim oluşur. Entografi araştırmalarının özünü oluşturan bu iki faaliyet genel olarak daha önceden aşina olunmayan bir sosyal çevreye birebir katılım ve bu katılıma dayalı olarak ortaya çıkan yazılı anlatılar şeklinde ifade edilebilir (Emerson vd., 2015: 1).

Ancak yukarıda ifade edilen durumlar etnografik araştırmayla ilgili birçok tartışmayı da beraberinde getirmiştir. Nitekim katılımcı gözlem klasik etnografinin bir yöntemi olarak görülür, yerli ve araştırmacı arasındaki ayrımı ortaya çıkaran bu durum antropolojik bakışın kolonyal geçmişine referansla olumsuz bir şekilde nitelenir. Bu anlamda araştırmacının konumsallığı, düşünümsellik ve özdüşünümsellik üzerinde yürütülen tartışmalar bugünkü etnografik bakışın ana hatlarını şekillendirmiştir (bkz. Atay, 2017; Harmanşah ve Nahya, 2018; Kayaalp, 2014).

İlk olarak etnografik diyaloğun niteliği ve süreci üzerine yoğunlaşan etnografya 1970' li yılların başında katılımcı gözlem tartışmalarından katılımın gözlemlenmesine doğru bir değişim yaşamıştır. Katılımcı gözlem sırasında etnograflar başkalarının yaşamlarının hem duygusal hem de soğukkanlı gözlemcileri olmaya çalışırken bu durum katılımın gözlemlenmesinde etnografın kendi ve başkalarının birbirleriyle olan ilişkilerini hem tecrübe etmesi hem de gözlemlemesi şeklinde değişmiştir. $\mathrm{Bu}$ anlamda etnografik araştırmada gerçekleşen metodolojik dönüşüm benlik üzerine merkezileşen bir etnografi anı veya diğeri üzerinde merkezileşen standart bir monograf yazımı arasında bir tercih yapmak yerine hem "Benliğin" hem de “Öteki”nin tek anlatı içinde birlikte sunulduğu anlatımsal bir dönüşüm olarak değerlendirilebilir (Tedlock, 1991:69). Bu dönüşümle etnografik yöntemle elde edilen bilgi yalnızca öteki hakkında bilgi olmayıp ben ve ötekinin birbirini karşılıklı biçimde tanımlamasından ortaya çıkan bir bilgi niteliği kazandı. Böylelikle klasik etnografi anlayışına karşı etnografik etkinliği bir diyalog ve antropolog ile topluluk üyeleri arasında bir etkileşim olarak kavrayan "diyalojik etnografi" anlayışına gelinmiş oldu (aktaran Atay, 2017: 199). Söz konusu bu durumla birlikte bir zamanlar kesin ve net bir şekilde tanımlanmış ötekilere bakarak onları tanımlayan antropoloji anlayışının yerini "ötekilere" kendisiyle ilişkileri bağlamında yaklaşan ve bunu yaparken bir anlamda kendisini ötekileştiren bir anlayış almış oldu. Böylelikle ilgi tanıtılan kültür yerine tanıtan antropolog/araştırmacı üzerinde yoğunlaştı (Atay, 2017: 203).

Diğer taraftan nitel araştırmalarda araştırmacının araştırma süreci boyunca konumu, bu konumun alacağ değişik boyutlar ve bunların araştırma üzerindeki muhtemel etkilerinin farkına varılması noktasında "düşünümsellik" gündeme gelmektedir (Kaçar-Tunç, 2020). Düşünümsellik konumsallığının araştırma sürecini ve sonucunu etkileyebileceğinin kabul edilmesiyle araştırmada bir öz değerlendirme, sürekli bir iç diyalog süreci olarak tanımlanabilir (Berger, 2015:220). Bir başka deyişle düşünümsellik kendi hakkımızda düşünmek, kendimizi kendimize sergilemektir (aktaran Zırh, 2017:68).

Etnografik araştırmalarda düşünümsellik çalışmanın bağlamını, ne tür koşullar altında yapılıp yazıldığını ve araştırmayı yönlendiren etmenleri kritik olarak düşünmenin gerekliliğine vurgu yapar. Bu şekilde araştırmacı, alanda kendi rolünün ve diğer öznelerle ilişkisinin araştırma üzerindeki etkilerini kritik ederek araştırmasının, kullandığı yöntemlerin ve ulaştığı sonuçların bütünlüğü ve güvenilirliğini sağlayabilir. Nitekim bilginin üretilmesi noktasında alanda araştırmacı ile yerlinin kendi durumlarından kaynaklı güç dinamiklerinin olduğu bir gerçektir (Harmanşah ve Nahya 2018:24). Söz konusu güç ilişkileri nedeniyle bilginin üretimi aşamasında araştırmacı bir otorite sahibi olarak görülebilir. Araştırmacının bu otoritesi diğer insanların sahip olduğu zaaflardan uzak birinin, alanın portresini mutlak bir kesinlikle yani yanlışlanamaz bir eda ile anlatması biçiminde belirginleşir (Atay, 2017: 196). Bu anlamda düşünümsel metinlerin araştırma sürecinde üretilen güç ilişkilerinin açığa çıkarılması, bu ilişkilere eleştirel bir bakış açısı kazandırması ve bu konuda bir bilinç ortaya çıkarması söz konusu olmaktadır. Bu sebeple özdüşünümsel metinler en az araştırmanın sonuçları kadar gerekli ve kritik bir bakış açısı sunar (Harmanşah ve Nahya, 2018:25-27).

Klasik etnografiye yönelik bir başka tartışma da alanla ilgilidir. Deneyimin yaşandığı "alan" klasik antropolojinin yaklaşımında, sosyal ve beşeri bilimlerin geneline benzer bir şekilde, insanların yaşadığı tek parçalı bir bütün sınırlandırmasının içinde tanımlanır. Ancak bugün kimi araştırmacılar alan kapsamının çok sahalı olabileceği görüşündedirler. Araştırmacının birden fazla sahada dolaşarak gerçekleştirdiği araştırmada çok sahalı alan mesafeleri ve farklılıkları birleştirmektedir (Harmanşah ve Nahya, 2018:19). 
Klasik etnografinin yöntemine ilişkin getirilen bu eleştirilerle uzaklarda bir yerlerde yerlilerin otantik kültürünü inceleme konusu yaparak bunları Batı'da temsil eden anlayış, yerini daha önceden görmezden gelinen bürokrasi, kurumlar, şirketler, piyasa, bilim ve teknoloji gibi alanları çözümleyen ve burada var olan iktidar ağlarını sorgulayan bir anlayışa bırakmıştır. Böylelikle ilgi “öteki”nden başka bir yöne kayarak Batı medeniyetini ve sömürgeciliğini sorgulayan, devletin marjinlerini araştıran ve kapitalist dönüşümü inceleyen etnografik çalışmalar yapılmaya başlanmıştır. Bu çalışmaların birçoğunda vurgu "öteki” nin bir kültürel özne olarak temsil edilmesi meselesinden, özneleri farklı şekillerde kuran iktidar süreçlerinin incelenmesine kayarak bu süreçlerde bilginin nasıl ve kimler tarafından inşa edildiği meselesi önemli bir sorgulama alanı olarak belirmiştir. Çalışma konularında söz konusu olan bu eksen kayması etnografik araştırmalardaki arayışları yeniden başlatarak öznesi sadece insan ve kültür olan antropolojik çalışmalar yerini çok failli, çok alanlı saha araştırmalarına bırakmıştır (Kayaalp, 2014:104-105).

Marcus'(1995)'un “multi-sited ethnography” olarak kavramsallaştırdığı çok alanlı etnografi farklı alanların çoğullaştırılmasını ifade etmektedir. Bundan kasıt niceliksel bir çoğullaştırma durumu değildir. Söz konusu olan farklı şirketleri, sivil toplum kuruluşlarını, köyleri, kasabaları vs. içine alan bir saha araştırmasıdır (Kayaalp, 2014:107). Marcus (1995:97)' a göre postmodernizmin entelektüel sermayesi etnografideki bu yeni yaklaşımın ortaya çıkmasına yönelik bir çerçeve sağlamıştır.

\section{MEDYA ÇALIŞMALARINDA ETNOGRAFIKK YÖNTEM}

Disiplinlerarası bir olgu olarak değerlendirilen etnografinin uygulama alanı "kültürün" yeni sorunlu bir tanımlama ve eleştiri nesnesi olduğu birçok alana yayılmaktadır (Clifford,1986:3). Bu anlamda sosyal ve kültürel antropolojide her zaman baskın bir yöntem olan etnografi artık sosyoloji, sosyal psikoloji, eğitim ve sağlık gibi alanlarla birlikte (Hammersley, 2006: 11) medya çalışmalarını da kapsamına almıştır (Marcus, 1995: 103).

1990'larda disiplinlerarası bir yaklaşımla antropolojinin medya çalışmaları ile yoğun bir şekilde etkileşimi sonucunda medya ürünlerinin üretim ve tüketim süreçleri antropolojinin yeni konuları olarak belirmiş ve böylece medya antropolojisi yeni bir çalışma alanı olarak kendisini göstermeye başlamıştır (Kaptan, 2016: 164).

Antropologlar dünya çapındaki kültürlerin medyaya atıfta bulunulmaksızın artık anlaşılamayacağını giderek daha fazla fark etmeye başlamışlardır (Bird, 2010:85). Nitekim dünya çapında hızla yaygınlaşmaya başlayan medya insanların günlük yaşamlarının bir parçası haline gelmiş böylelikle birey ve toplum üzerinde önemli etkiler ortaya çıkarmaya başlamıştır. Bu yönüyle medya dünyada olup bitenlerin anlamını müzakere etmede, toplumların değerleri, inançları ve normları hakkında bilgi edinme ve bireylerin kimlik gelişiminde söz sahibi olmuş ve dolayısıyla yaşam tarzlarını, kültürleri ve toplumları şekillendirmede giderek daha merkezi bir rol oynamaya başlamıştır (Williams, 2003:6). Diğer taraftan gerçek kültürü bir hammadde olarak kullanan ve bu kültürü çeşitli yönlerden değiştirerek, şekillendirerek ve yeniden üreterek kullanıma sunan medya modern insanın kültürel tercihlerini düzenlemekte ve onun dünyaya ilişkin imgelerini tasarlaması noktasında katk1 sunmaktadır (Lundby ve Ronnig:2014:18). Nihai olarak modern insanın zamanının çoğunu medya karşısında geçiriyor olması da medya kültürünün günlük hayatta egemen kültür olarak konumlanmasına yol açmıştır (Kellner, 1995:2-3). Bu anlamda medya egemen kültür olarak insanlara çeşitli düşünme biçimleri ve davranış modelleri önererek sosyal yaşamı önemli ölçüde biçimlendirmektedir (McQuail, 2005:4).

Tüm bu durumlar antropologların da fark ettiği gibi toplumsal yaşamın önemli bir parçası haline gelen medyanın toplumsal analizlerde merkezi bir konumda olması gerektiğini göstermektedir. Nitekim medya yaygınlaştıkça ve her yerde bulunur hale geldikçe, günlük yaşam kategorilerinin sürekli yeniden düzenlenmesinde merkezi bir rol oynamaya başlamıştır (Deuz, 2011:127). Bu duruma ilişkin olarak Williams (2003:7) medyanın toplumsal yaşam üzerindeki etkisinin çok önemli olduğunu ve medyanın rolünü kabul etmeden sosyal ilişkileri tartışmanın imkânsız olacağını belirtmektedir. Benzer şekilde Thampson da (2008:14) modern toplumların kurumsal özelliklerini ve bu toplumlar tarafından ortaya çıkarılan yaşam koşullarını anlamak için medyanın gelişimine ve etkisine merkezi bir rol vermenin zorunlu olduğunu belirtmektedir. Silverstone (aktaran Morley, 1992) ise daha radikal olarak televizyonun günlük yaşam olduğunu ve birini incelemenin aynı zamanda diğerini incelemek olacağını söylemektedir.

Antropologların medyayı bu gerekçelerle araştırma nesnesi olarak görmelerinin yanında medya çalışmaları yürüten araştırmacıların da yeni bir perspektifle etnografik araştırmalara yönelmesi söz konusu olmuştur. Bu yönelimin temelinde medyaya karşı izleyici tepkisini temel alan çalışmaların darlığ ve medyanın nüfuzunun karmaşık yapısının bu tür yaklaşımlarla yakalanamayacağı anlayışının yattığı söylenebilir (Bird, 2010:85). Diğer taraftan nicel araştırmaların medyanın etkilerini anlama noktasındaki eksikliklerinin de son zamanlarda tartışılmaya başlanması ve medyanın gündelik yaşamın bir parçası olduğu görüşünün ağırlık kazanarak

Selçuk Üniversitesi Sosyal Bilimler Meslek Yüksekokulu Dergisi, Yıl: 2021 Cilt: 24 Sayı:1 
araştırmalarda bağlam vurgusunun yapılması da araştırma sürecindeki dönüşümün gerçekleşmesini sağlayan nedenlerdendir. Silverstone (1990) medyayı takip etmenin bu bağlam içinde anlaşılabilen karmaşık bir yapı olduğunu ileri sürerken (aktaran, Morley, 1992: 165) Morley bu karmaşık faaliyet alanı hakkında yoğun bir betimleme yapabilmeye antropolojik ve etnografik bir bakış açısının yardımcı olacağını belirtmiştir (Morley, 1992:165-170). Nitekim bugün gündelik yaşamın tüm alanlarında medyanın izleri görülmektedir. İnsanların dini yaşantılarından siyasal eylemlerine, tüketim alışkanlıklarından yeme içme ritüellerine, sosyal ilişkilerden bürokratik ilişkilere değin birçok alanda medya üretici ve dönüştürücü bir rol üstlenebilmektedir. Tüm bunlar yukarıda da ifade edildiği gibi belirli bir bağlam içinde gerçekleşen karmaşık süreçlerdir. Kültür örüntüleri bu karmaşık süreçlerin bir sonucu olarak ortaya çıkar. Bu nedenle medyanın kültür ve toplum üzerindeki rolünü değerlendirirken gündelik yaşamdaki faaliyet alanlarının her birinin diğeriyle bağlamı içinde ele alınmasının daha anlamlı sonuçlar ortaya çıkaracağını söylemek mümkündür. Örneğin dini inançların siyasal tercihler, tüketim alışkanlıkları, ekonomik faaliyetler, sosyal ilişkiler gibi toplumsal yaşamın tüm alanlarını kapsayıcı bir etkisi söz konusudur. Bu noktada medyanın dini inançlara yönelik göstereceği etkinin diğerlerinde de bazı değişimler meydana getireceği öngörülebilir.

$\mathrm{Bu}$ anlamda yeni bir alan olarak ortaya çıan medya antropolojisi ve medya etnografisi modern toplum ve kültürleri anlamak için gerekli epistemolojik çerçeveyi sunmanın yanısıra medyanın analiz edilmesi için temel metodolojik bir yaklaşım sağlamaktadır (Kaptan, 2016:163-164).

Medya etnografisinin öncü isimlerinden olan Postill (2017:23) medya etnografisi için iki temel aşamadan bahsetmektedir. İlk aşama 1980'lerin ve 1990'ların televizyon çalışmalarının yer aldığı çıkış aşaması, ikinci aşama ise 2000'lerden günümüze kadar teorik yenilik ve medya çeşitliliğinin dikkat çektiği aşamadır. Yirminci yüzyıl sonları olan ilk aşamada büyük ölçüde radyo, televizyon, film, video ve yazılı basın gibi dönemin baskın medyasının ele alındığı etnografik çalışmalarından oluşur. 2000 ve 2010'ları kapsayan ikinci aşama ise medya etnograflarının televizyon, radyo ve filme gösterdiği ilgi devam etmekle birlikte sosyal ve mobil medyaya daha fazla ilgi duyduğu dönemi ifade eder.

Malezya ve İspanya'da etnografik araştırmalar yürüten Postill (2017) etnografik medya çalışmalarında diyakronik (artsüremli) bir etnografiyi yaşanan büyük siyasal dönüşümleri ve toplumsal değişimleri kavramayı amaç edinmesinden dolayı önemli görür. Burada Postill'in diyakronik etnografiyle kastettiği şey, Marcus'un önerdiği şekilde çok alanlı etnografiyle (multi-sited ethnography) birlikte çok zamanlı (multi-timed ethnography) bir etnografidir. Burada çok-alanlı etnografi daha önce de ifade edildiği gibi farklı etkenlerin ve aktörlerin hesaba katıldığı, onları birbirleri ile bağlantılandıran çoğul perspektifli bir bakışı ifade eder. Çok zamanlı etnografi ise aynı alanlara farklı zamanlarda gitmeyi ve burada yaşanmış olan toplumsal değişimlerin izini sürmeyi ifade eder. Postill'in medya etnografisiyle ilgili önerisi, saha araştırması yapılan yerdeki büyük değişimlerin medyadaki izdüşümlerini yakalamak ve yaşananları medya kullanım pratikleri açısından görebilmektir (Çayl1-Rahte, 2018:604).

Medya etnografisinde hem üretim süreçlerinin hem de tüketim süreçlerinin bir arada ele alınabilmesi (bkz. Çaylı Rahte, 2009) farklı etkenleri ve aktörleri değerlendirme konusu yapması açısından çok alanlı etnografi örneği göstermektedir. Karmaşık kültürel süreçleri ele almanın bir yolu olarak görülen çok alanlı etnografi medyada yapılan alımlama ve üretim odaklı çalışmaları birleştirerek araştırmacılar için en verimli araçlardan birini sağlamıştır. Bu bağlamda günümüzde medya etnografisi medya ve iletişim alanında çalışan akademisyen ve araştırmacılara birçok firsatı bir arada sunan ve yeni bir bakış açısı sağlayan bir alan olarak büyük bir gelişme göstermektedir (Kaptan, 2016:174).

Tüm bunlara karşın bir yöntem olarak etnografinin sınırlarını koruma çabaları medya etnografisi gibi yeni alanlardaki araştırmaları da tartışmaya açabilmektedir. Bu konudaki en başat çalışmalardan birisi Ingold (2017)'un "Bu Kadar Etnografi Yeter” adlı çalışmasıdır. Söz konusu çalışmasında Ingold (2017:173-175) etnografinin hem antropolojide hem de diğer bağlantılı alanlarda fazlaca kullanılan bir terim haline geldiğini ve anlamını büyük ölçüde yitirdiğini ifade etmektedir. Ona göre "etnografik araştırmayı kişilerle yapılan görüşmelere veya daha genel olarak alan çalışmasına dayandırmak, antropolojinin bir disiplin olarak, gerek ontolojik taahhüdünü gerekse eğitsel amacını ve temel çalışma prensibini yani katılımcı gözlemi zayıflatmaktır". Daha genel olarak etnografinin niteliksel araştırmanın yerine kullanılması antropolojik araştırmanın bütün ilkelerini ihlal etmektedir.

O halde medya antropolojisi ya da medya etnografisi dediğimizde bunun da sınırlarının iyi belirlenmesi gerekmektedir. Derinlemesine görüşmelerin veya diğer niteliksel desenlerin etnografik yöntem olarak anılması Ingold (2017)' un endişelerini haklı çıkarmaktadır. Bu anlamda medya etnografisi yaparken izleyicileri doğal ortamında incelemek ve izleme ediminin karmaşık toplumsal süreçlerle ilişkisini göz önünde bulundurarak yoğun betimlemeler yapmak (aktaran, Çaylı-Rahte 2009:67) söz konusu çalışmalar için en kritik nokta olarak değerlendirilebilir.

Selçuk Üniversitesi Sosyal Bilimler Meslek Yüksekokulu Dergisi, Yıl: 2021 Cilt: 24 Sayı:1 
Nitekim bir topluluğu kendi gündelik yaşamının akışı içinde, o akışa katılarak gözlemlemek etnografi için saha çalışmasının temel koşulu olarak görülür (akt. Ergül, 2013:5). Bir bakıma katılarak gözlem yoksa etnografi de yoktur. Katılımcı gözlem bu sebeple etnografi açısından son derece önemli bir nokta olarak karşımıza çıkar. $\mathrm{Bu}$ anlamda etnograftan beklenen de çalışma sürecinde içerden bir yaklaşım geliştirerek belirlediği konu ekseninde gündelik örüntüleri gözlemlemesi ve yorumlamasıdır (Ergül, 2013:5).

Çaylı-Rahte (2018) medya çalışmalarının bu konudaki eksikliklerini ele almakta ve Türkiye'de yapılan medya etnografisi çalışmalarının sorunlu yönlerini ortaya koymaktadır. Söz konusu çalışmasında Çaylı-Rahte medyayı etnografik olarak araştırma konusu yaptığını ifade eden çalışmaların genelinde etnografi yapmayı saha araştırması yapmakla özdeş görme eğiliminin olduğunu ve genel olarak medya etnografísinin gözlem ve görüşme gibi nitel araştırma tekniklerinin medya araştırmalarına uygulanması şeklinde değerlendirildiğini belirtmektedir.

$\mathrm{Bu}$ anlamda medya etnografisi yapabilmek için aşağıdaki kriterlerin yerine getirilmesi gerekmektedir (Çayl1-Rahte, 2018):

- Çalışmanın alan araştırması içermesi,

- Alan araştırmasının katılarak gözleme yer vermesi,

- Derinlemesine görüş̧emelerin yapılması,

- Yapılan bu görüşmelerin kişilerin gündelik hayat pratiklerine ve kültürel, sosyal, politik ilişkilenme biçimlerine dair yoruma ulaşmaya imkan verecek bütüncül bir yaklaşım ile kurgulanmış olması,

- Görüşülen ya da gözlemlenen kişilerin ifadeleri, görüşleri, düşünce ve duygularına metinde yer verilmesi,

- Alan araştırmasının yeterince uzun süreli olması

- Görüşülen kişi sayısının etnografik bir çalışma için yeterli olması

Çayl1-Rahte'ye göre "bu sıralananlar içerisinde "etnografi yapmak" açısından belirleyici olanlar, son dört maddede yazılı olanlardır. Katılarak gözlem ya da derinlemesine görüşme yapmaktan ziyade görüşülenlerin gündelik hayat pratiklerini bir bütün olarak görebilmek ve onların seslerini metne dönüştürebilmek etnografi yapmada ağırlık kazanmaktadır. Sahada kalınan süre açısından da antropolojik saha araştırmalarındaki kadar uzun süreli alan araştırmaları ve görüşülen kişi sayısı olarak da nicel araştırmalardaki kadar büyük rakamlar söz konusu olmasa da bütünlüklü bir yoruma ulaşmak ve alana "nüfuz edebilmek" açısından, belli sayıda kişi ile, yeterli süre sahada bulunarak görüşme yapmak da medya etnografisi yapmak açısından belirleyici olabilmektedir."(2018:616-617).

\section{TARTIŞMA VE SONUÇ}

Kültürel antropolojinin temel bir yöntemi olarak ortaya çıkan etnografi günümüzde disiplinlerarası bir konumda yer almaktadır. Çok çeşitli disiplinlerin araştırma yaparken kullandığı bu yöntem görece yeni olsa da medya çalışmalarında da kullanılmaktadır. Medyanın kültür üzerinde önemli bir etkiye sahip olması bir yandan medyayı antropolojik çalışmaların odağı haline getirirken, diğer yandan medya çalışması yapan akademisyenlerin çalıştığı kitleyi daha derinlemesine analiz etme saikleri bu alanda etnografiye olan ilgiyi artırmıştır.

Medyada etnografik yöntemin kullanılması birçok açıdan diğer yöntemlerin sınırlılıklarını aşmaya yönelik bir amaç taşımaktadır. Örneğin nicel araştırmaların sahip olduğu yapılandırılmış karakter nedeniyle hem sınırlı bir alanın ele alınması hem de yüzeysel bir bilgiyle yetinilmesi gibi eksiklikleri ya da sadece izleyici üzerinden medya tüketim süreçlerini ele alan veyahut medya ürünlerinin üretim aşamalarını inceleyen tek boyutlu bir araştırma tasarımı medya etnografisiyle aşılmaya çalışılmaktadır. Buna yönelik olarak medya etnografisi çok alanlı bir karakter taşımakta ve araştırmacılara hem medya ürünlerinin üretim aşamasını hem de tüketim aşamasını bir arada ele alma imkanı tanımaktadır. Böylelikle bir yandan üretim aşamasında yer alan medyanın çalışma şekliyle ilgili bilgiler elde edilirken bir yandan da medyanın izleyiciler üzerindeki etkileri ortaya koyulabilmektedir. Her ikisini de bir araştırma tasarımı içinde incelemenin en önemli avantajı ise üretim ve tüketim aşamasını birbirinden kopuk olarak değil birbiriyle bağlantılı olarak inceleme firsatı vermesidir.

Ancak etnografi sınırları belirli bir alandır ve her araştırmada olduğu gibi etnografik araştırma yapmanın da belirli kriterleri söz konusudur. Bu anlamda yapılan araştırmalarda etnografik yöntemin kendi kriterlerine bağlı kalmak ve bu kriterler üzerinden araştırmayı yürütmek önem taşımaktadır. Görece yeni bir alan olması dolayısıyla medya etnografisi yaptığını söyleyen çalışmaların bu kriterleri ne kadar taşıdığı tartışma konusudur. Diğer yandan medya etnografisi sınırları içine giren çeşitli yöntemlerin de etnografik araştırma kriterlerini ne kadar taşıdığı da tartışılabilir.

Bu anlamda iletişim çalışmalarında medya etnografisini kullanmak birçok açıdan avantaj sağlasa da bunun etnografik yöntemin kuralları çerçevesinde yapılmaması bu avantajların önüne geçecektir. Daha da önemlisi

Selçuk Üniversitesi Sosyal Bilimler Meslek Yüksekokulu Dergisi, Yıl: 2021 Cilt: 24 Sayı:1 
bu tür çalışmalarda etnografik araştırmanın kurallarının göz ardı edilmesi yöntemsel bir kargaşanın da ortaya çıkmasına sebep olacaktır.

$\mathrm{Bu}$ açıdan iletişim çalışmalarında medya etnografisi yapan araştırmacıların etnografik yöntemin kriterlerine azami surette riayet etmeleri, buna riayet etmeyen çalışmaların yeni bir araştırma tasarımı ortaya koyma endişesiyle "etnografi” olarak adlandırılmaması önemli bir gereklilik olarak karşımıza çıkmaktadır. 


\section{KAYNAKÇA}

Atay T. (2017). Sosyal Antropolojide Yöntem ve Etik Sorunu: Klasik Etnografiden Diyalojik Etnografiye Doğru, Moment/Hacettepe Üniversitesi İletişim Fakültesi Kültürel Çalışmalar Dergisi, 4(1) s. 189-206.

Berger, R. (2015). Now I See It, Now I Don't: Researcher's Position And Reflexivity in Qualitative Research. Qualitative Research, 15(2) 219- 234.

Bird, S.E. (2010) 'From Fan Practice to Mediated Moments: The Value of Practice Theory in the Understanding of Media Audiences',in B. Bräuchler and J. Postill (Eds). Theorising Media and Practice, içinde (s. 85-104) New York/Oxford, Berghann Books.

Can, B. (2017). Gündelik Hayat, İktidar İlişkileri ve Etik Kodların Kesişiminde Etnografik Araştırma. Moment/Hacettepe Üniversitesi İletişim Fakültesi Kültürel Çalışmalar Dergisi 4(1). s. 155-172.

Clifford J. (1986) Introduction, Partial Truths, Writing Culture. Clifford J. ve Marcus E. G. (ed). Writing Culture: The Poetics and Politics of Ethnography içinde (s. 1-27). Los Angeles: University of California Press.

Çaylı Rahte E (2009). Kamusallık, Mahremiyet ve Medya: 'Kadın Tartışma Programları' Üzerine Etnografik Bir Araştırma. Yayımlanmamış Doktora Tezi. Ankara: Ankara Üniversitesi Sosyal Bilimler Enstitüsü.

Çaylı Rahte E (2018). Türkiye'de Medya Etnografisi Yapmak: Alanın Gelişimi ve Seyrine Eleştirel Bir Bakış. Mülkiye Dergisi, 42 (4), 593-637.

Deuz, M. (2011). Media life. P. Stylianos (Ed.). Media perspectives for the 21st century: Concepts, topics and issues içinde (s. 137-149). London: Routledge.

Emerson, R.M., Fretz, R.I., Shaw, L.L. (2015). Alan Çalışması: Etnografik Alan Notları Yazımı (Çev. Erkan Koca). Ankara: Atıf Yayınları.

Ergül, H. (2013). İletişim Araştırmalarında Etnografik Yöntem. İstanbul: İstanbul Bilgi Üniversitesi Yayınları.

Greetz, C. (1973). The interpretation of cultures. New York: Basic Books.

Hammersley, M. (2006). What's Wrong With Ethnography, Methodological Explorations, New York, USA: Routledge.

Hammersley, M. ve Atkinson, P. (2007). Ethnography: Principles in Practice. New York, USA: Routledge.

Harmanşah, R. ve Nahya, Z. N. (2018). Etnografik Hikâyeler. İstanbul: Metis.

Ingold, T. (2017). Bu Kadar Etnografi Yeter (Çev. Beren Kandemir). Moment/Hacettepe Üniversitesi İletişim Fakültesi Kültürel Çalışmalar Dergisi 4(1). 173-188.

Kaçar-Tunç, G. (2020). Nitel Araştırmalarda Konumsallık ve Düşünümsellik: Yakınlık ve Mesafe Arası Müzakere. Humanitas, 8(16), 249-266

Kaptan, Y. (2016). Reklamcılık Çalışmalarında Medya Etnografisinin Önemi: Çok Alanlı Etnografiler. Selçuk İletişim, $9(3), 162-177$.

Kartarı, A. (2017). Nitel Düşünce ve Etnografi: Etnografik Yönteme Düşünsel Bir Yaklaşım. Moment/Hacettepe Üniversitesi İletişim Fakültesi Kültürel Çalışmalar Dergisi 4(1). s 207-220.

Kayaalp, E. (2014). Etnografik Çalışmalarda Yeni Arayışlar, Alanlar ve Failler. Ramazan Aras (ed.) Sınırları Aşmak: Türkiye'de Sosyo-Kültürel Antropoloji ve Disiplinlerarası Yaklaşımlar içinde (s. 104-122). Konya: Çizgi

Kellner, D. (1995). Media Culture: Cultural Studies, Identity and Politics Between the Modern and the Postmodern, London: Routledge.

Lundby, K, Ronning, H. (2014). "Medya-Kültür-İletişim: Medya Kültürü Aracıllı̆ıyla Modernliğin Yorumlanışı" (Ed. Süleyman İrvan) Medya, Kültür, Siyaset, Ankara: Pharmakon Yayınevi.

Marcus, G.E. (1995). Ethnography in/of The World System: The Emergence Of Multi-Sited Ethnography. Annual Reviews Antropology. 24, 95-117.

Mcquail, D. (2005). McQuail's Mass Communication Theory (5th. Edition), London: Sage Publications.

Morley D.(1992). Television, Audiences, and Cultural Studies, London, Routledge.

Neuman, W.L. (2020). Toplumsal Araştırma Yöntemleri: Nicel ve Nitel Yaklaşımlar Cilt I, Ankara: Siyasal Kitabevi.

Özbölük, T, Dursun Y (2015). Pazarlama Araştırmalarında Paradigmal Dönüşüm ve Etnografinin Dijitale Evrimi: Netnografi. Erciyes Üniversitesi İktisadi ve İdari Bilimler Fakültesi Dergisi, Sayı: 46, Temmuz-Aralık 2015. 227249

Postill J (2017). The Diachronic Ethnography of Media: From Social Changing to Actual Social Changes. Moment/Hacettepe Üniversitesi İletişim Fakültesi Kültürel Çalışmalar Dergisi.4(1). 19-43.

Spitulnik D (1993). Anthropology and Mass Media. Annual Review of Anthroplogy. Vol. 22. s 293-315.

Tedlock, B. (1991). From participant observation to the observation of participation: The emergence of narrative ethnography. Journal of anthropological research, 47(1), 69- 94.

Thampson, J. B. (2008). Medya ve Modernite, (Çev. Serdar Öztürk), İstanbul: Kırmızı Yayınları.

Williams, K.(2003). Understanding Media Theory, London: Arnold.

Zırh C.B. (2017). Alevi-Olmayan Bir Araştırmacı Olarak Alevilik Üzerine Çalışmak: Göç-Mekânda Ama Evde ÇokAlanlı Etnografi. Moment/Hacettepe Üniversitesi İletişim Fakültesi Kültürel Çalışmalar Dergisi 4(1). 52-72. 